\title{
Comparison of the Use of H1N1 and seasonal influenza vaccinations between veterans and non-veterans in the United States, 2010
}

\author{
Claudia Der-Martirosian ${ }^{1 *}$, Kevin C Heslin ${ }^{1,3}$, Michael N Mitchell ${ }^{1}$, Karen Chu', Kim $\operatorname{Tran}^{2}$ and Aram Dobalian 1,2,3
}

\begin{abstract}
Background: Veterans of the U.S. armed forces tend to be older and have more chronic health problems than the general adult population, which may place them at greater risk of complications from influenza. Despite Centers for Disease Control and Prevention (CDC) recommendations, seasonal influenza vaccination rates for the general adult population remain well below the national goal of $80 \%$. Achieving this goal would be facilitated by a clearer understanding of which factors influence vaccination.

Methods: Using the 2010 U.S. National Health Interview Survey (NHIS), this study estimates models of two types of vaccinations ( $\mathrm{H} 1 \mathrm{~N} 1$ and seasonal flu), assesses if the correlates differ for these vaccinations, and analyses the distribution of the correlates by veteran status.

Results: Veterans, women, non-Hispanic whites, non-smokers, those at high risk, educated, with health insurance, and who use clinics as a usual source of care were more likely to receive both types of vaccinations. Those who were older, married, and with higher income were more likely to get vaccinated for seasonal flu, but not for H1N1. Age and number of children living in the household were found to have different effects for H1N1 compared to seasonal flu.

Conclusion: Veterans are more likely to get vaccinated for seasonal influenza and H1N1 compared to the general population. This might be due to Veterans having better access to care or Veterans participating in better health care practices. Future studies should examine potential differences in flu vaccination use among Veterans using Veterans Affairs (VA) health care system vs. non-VA users.
\end{abstract}

Keywords: H1N1, Seasonal flu shot, Veterans, non-Veterans, flu vaccination

\section{Background}

Influenza outbreaks occur nearly every year, and cost the U.S. economy an estimated \$71-167 billion per year in health services use and lost productivity [1]. Influenzarelated diseases also cause an estimated 225,000 hospitalizations and 36,000 deaths annually in the U.S., mostly among chronically ill or elderly people [2-4]. In 2010, the Centers for Disease Control and Prevention (CDC) and the Advisory Committee on Immunization Practices (ACIP) recommended annual influenza vaccination for all persons aged $\geq 6$ months [5], and this recommendation still

\footnotetext{
* Correspondence: claudia.der-martirosian@va.gov

${ }^{1}$ Veterans Emergency Management Evaluation Center (VEMEC), Department of Veterans Affairs, North Hills, California, USA

Full list of author information is available at the end of the article
}

continues to be in effect [6]. Despite the ACIP recommendations, vaccination rates among the general population remain well below the national Healthy People 2020 goal of $80 \%$ [7]. Studies show that vaccination use among high-risk groups in the U.S. remains suboptimal, ranging between $45 \%$ and $68 \%$ [2,8-12]. Similarly, during the H1N1 epidemic in 2009 H1N1 vaccination rates were below national goals in the U.S., only about $50 \%$ of those with diabetes and chronic lung diseases and less than $40 \%$ of adults with asthma were vaccinated by mid-November 2009 [5,13-15].

H1N1 and seasonal flu vaccination is critical for all Veterans of the U.S. armed forces, who tend to be older than the general adult population [16], and especially for VA users who are more likely to suffer from multiple health conditions compared to the general population [17].

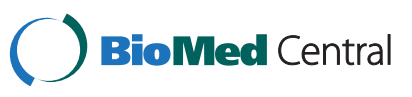


According to the U.S. Census Bureau, there are approximately 22 million veterans in the U.S., and about a quarter use the VA health care system nationwide [18]. Previous work has shown that the prevalence of influenza vaccination among VA system users is approximately $75 \%[19,20]$. Even though about three quarters of the U.S. Veteran population does not use VA services, previous work on the prevalence of vaccination among Veterans has, to our knowledge, focused almost exclusively on those who use VA services. Further, even though adult immunization use among VA patients is higher than it is in the general adult population, these immunization rates are still not optimal $[19,20]$. Similarly, in a nationally representative sample of adults with diabetes, Lynch et al. [21] illustrate that even though Veterans with diabetes were more likely to get vaccinated (than were non-Veterans with diabetes) after adjusting for relevant confounding factors, vaccination rates among adult Veterans with diabetes were below the national goal (68.2\% for Veterans vs. 31.8\% for non-Veterans). Achieving the Healthy People 2020 set an $80 \%$ goal for vaccination [7] is difficult without having a clear understanding of the factors that influence vaccination, which may also differ between Veterans and non-Veterans. Previous studies have found that several demographic and behavioral factors are associated with vaccination specifically, age [22], race/ ethnicity [10,23], marital status [24], education [24], and smoking [24].

Veterans include a range of persons with a high level of comorbid health conditions (e.g., higher rates of smoking, substance use disorders and other conditions compared to the general adult population) and other socioeconomic factors (e.g., homelessness) that place them among the more vulnerable members of the population [25]. Information on flu vaccination uptake comparing Veterans and nonVeterans is limited, especially on a nationally representative sample. Moreover, if the determinants of H1N1 and seasonal influenza vaccination use are different, then policies and programs aimed at increasing uptake of vaccination will need to differ in terms of outreach, resource allocation, and other characteristics. Using data from the 2010 U.S. National Health Interview Survey (NHIS) and applying the Andersen Behavioral Model of Health Services Use [26,27], this study estimates models of two types of vaccinations ( $\mathrm{H} 1 \mathrm{~N} 1$ and seasonal flu), assesses if the correlates differ for these vaccinations, and analyzes the distribution of the correlates by veteran status.

\section{Methods}

Data from the 2010 NHIS was used for this study. The NHIS is an annual survey conducted by the CDC's National Center for Health Statistics [28] that provides information on the health status of the U.S. non-institutionalized civilian population through personal household interviews. The NHIS is the nation's largest household health survey, providing data on health trends, barriers to care, health status, health related behaviors, and risk factors in the U.S. The NHIS is composed of several distinct datasets, of which three were used in this study: the Sample Adult Public Use File, the Persons Public Use File, and the Family Public Use File. The merging of these three data sets yielded a sample of 27,157 unique individuals. This study focuses on 1,342 Veterans who reported having been honorably discharged from active duty in the U.S. armed forces and 13,997 non-Veterans. The analytic sample was limited to non-missing data for the H1N1 question. Missingness was by design since the H1N1 question was removed from the NHIS in August 2010, which coincides with the end of the $2009 \mathrm{H} 1 \mathrm{~N} 1$ pandemic globally.

For this study, analyses of these public use data were exempted from review by the Institutional Review Board of the Department of Veterans Affairs Greater Los Angeles Healthcare System.

\section{Dependent variables}

Influenza vaccination status was assessed in the NHIS with the following questions: "During the past 12 months, have you had a seasonal flu shot?" and "Since October 2009, have you had a H1N1 flu vaccination?" The 2010 NHIS was the first year that collected information on $\mathrm{H} 1 \mathrm{~N} 1$ vaccination rates.

\section{Independent variables}

Age, sex, race/ethnicity, marital status, number of children under age of 18 living in household, education, and current smoking status represent the predisposing domain of the Andersen Model. Enabling factors included insurance coverage, annual household income, employment status, and usual source of care. The need domain of the model is represented by a derived variable on health risks that reflects the CDC's ACIP recommended groups for vaccination. High-risk individuals were defined as respondents who had any of the following conditions: asthma, cerebral palsy, epilepsy, stroke, intellectual disability, disabling birth defects, lung/breathing problems, emphysema, heart disease, angina pectoris, myocardial infarction, coronary heart disease, blood disorders, metabolic disorders, diabetes, weak/failing kidneys, liver disorders, hepatitis, cancer, arthritis, and current pregnancy.

All of the explanatory variables were categorical. The coding of the explanatory variables is illustrated in Table 1. Age was categorized into four groups: 18-24, 25-44, 45-64 and 65 and over. Mutually exclusive categories were constructed for number of children under age of 18 in household (none, 1-2 children, 3 children or more), education (did not complete high school, high school graduate or GED, some college, and college graduate or beyond), health insurance type (none, private, public/military), family income (\$0-\$14,999, \$15,000-\$34,999, $\$ 35,000$ and more), 
Table 1 Selected characteristics by Veteran status

\begin{tabular}{|c|c|c|c|c|}
\hline \multirow{2}{*}{\multicolumn{2}{|c|}{$\begin{array}{l}\text { Characteristic } \\
\text { Use of services (Dependent variables): }\end{array}$}} & \multirow{2}{*}{$\frac{\text { Veterans }}{\%^{\mathrm{a}}}$} & \multirow{2}{*}{$\frac{\text { Non-Veterans }}{\%^{\mathrm{a}}}$} & \multirow[t]{2}{*}{$\mathrm{p}$-value } \\
\hline & & & & \\
\hline H1N1 Vaccinat & & 24.3 & 18.7 & $<0.001$ \\
\hline Seasonal Flu V & & 49.0 & 32.7 & $<0.001$ \\
\hline \multicolumn{5}{|c|}{ Predisposing Variables: } \\
\hline Age & $18-24$ & 7.9 & 34.1 & $<0.001$ \\
\hline \multirow[t]{3}{*}{ Categories } & $25-44$ & 29.7 & 40.0 & \\
\hline & $45-64$ & 23.4 & 12.4 & \\
\hline & $65 \&$ up & 39.0 & 13.4 & \\
\hline Gender & Male & 92.9 & 44.0 & $<0.001$ \\
\hline \multirow[t]{4}{*}{ Race } & White & 80.7 & 66.5 & $<0.001$ \\
\hline & Black & 11.0 & 12.3 & \\
\hline & Hispanic & 6.0 & 15.4 & \\
\hline & Other & 2.3 & 5.8 & \\
\hline Marital & Married & 64.0 & 53.6 & $<0.001$ \\
\hline \multirow[t]{2}{*}{ Status } & Divorced/Separated/Widowed & 25.5 & 18.7 & \\
\hline & Never Married/Single & 10.5 & 27.7 & \\
\hline Children & None & 79.6 & 60.4 & $<0.001$ \\
\hline$(<18)$ Living & 1-2 Children & 17.2 & 30.5 & \\
\hline in Household & 3 or More Children & 3.2 & 9.1 & \\
\hline \multirow[t]{4}{*}{ Education } & Did not complete high school & 8.3 & 15.2 & $<0.001$ \\
\hline & High school graduate or GED & 30.3 & 26.7 & \\
\hline & Some college & 35.6 & 30.5 & \\
\hline & College graduate or beyond & 25.9 & 27.6 & \\
\hline Smoking & Yes & 22.4 & 19.7 & 0.041 \\
\hline \multicolumn{5}{|c|}{ Enabling Variables: } \\
\hline Health & None & 8.6 & 19.8 & $<0.001$ \\
\hline \multirow[t]{2}{*}{ Insurance } & Private & 35.9 & 55.5 & \\
\hline & Public/Military & 55.5 & 24.8 & \\
\hline Family & $\$ 0-\$ 14,999$ & 27.5 & 33.7 & $<0.001$ \\
\hline \multirow[t]{2}{*}{ Income } & $\$ 15,000-\$ 34,999$ & 17.5 & 14.7 & \\
\hline & $\$ 35,000 \&$ up & 55.0 & 51.6 & \\
\hline Employed & Yes & 45.7 & 61.9 & $<0.001$ \\
\hline Usual & Clinic & 17.7 & 16.3 & $<0.001$ \\
\hline Source of & MD Office & 65.1 & 62.7 & \\
\hline \multirow[t]{2}{*}{ Care } & Neither Clinic/MD Office & 8.0 & 3.5 & \\
\hline & None & 9.3 & 17.5 & \\
\hline \multicolumn{5}{|c|}{ Need Variable: } \\
\hline \multirow[t]{2}{*}{ High Risk $^{\mathrm{b}}$} & Yes & 66.0 & 46.5 & $<0.001$ \\
\hline & Unweighted Sample Size ( $N=15339)$ & 1,342 & 13,997 & \\
\hline
\end{tabular}

${ }^{a}$ Weighted predicted percents of the population.

${ }^{b}$ Currently pregnant, asthma, cerebral palsy, epilepsy, stroke, intellectual disability (mental retardation), birth defect that causes limitations/difficulty. with activities, lung/breathing problems, emphysema, heart disease, angina pectoris, myocardial infarction, coronary heart disease, blood disorders, metabolic disorders, diabetes, weak/failing kidneys.

'This is the $p$ value of the test of the association of the predictor by veteran status. Normally this would be a chi-square test, but accounting for the survey design (via the "svy" prefix) yields an F-test. The denominator degrees of freedom is 300 (reflecting the sample design) and the numerator degrees of freedom is the number of categories of the predictor minus 1 . 
and usual source of care (clinic, MD office, neither clinic or MD office, none).

\section{Statistical analysis}

All analyses were conducted with the Stata/SE software program (version 12.1). The "svyset" command was used to account for the complex sampling design (i.e., stratification, clustering, and oversampling) according to NHIS documentation [29]. The "svy" prefix was used in conjunction with estimation commands to account for the complex sampling design. Bivariate analyses were conducted to compare the distribution of sociodemographic characteristics and other relevant study variables between the Veteran and non-Veteran populations. Separate multiple logistic regression analyses were conducted with H1N1 flu vaccine (Model 1) and seasonal flu vaccine (Model 2), the two dependent variables. Adjusted odds ratios (ORs) and 95\% confidence intervals (CIs) were calculated for each explanatory variable. The two models were then jointly estimated (using the Stata "suest" command) comparing the size of the coefficients associated with $\mathrm{H} 1 \mathrm{~N} 1$ versus seasonal flu. The level of significance for all analyses was set at 0.05 .

\section{Results}

Table 1 compares the characteristics of Veterans and non-Veterans in the U.S. in 2010. The final sample consisted of 1,342 adult Veterans and 13,997 adult nonVeterans. H1N1 and seasonal influenza vaccination prevalence was higher for Veterans compared to nonVeterans (H1N1: $24.3 \%$ vs. $18.7 \%$; seasonal flu: $49.0 \%$, vs. $32.7 \%)$. Compared to non-Veterans, Veterans were more likely to be male, white, older, married, not to have children, unemployed, high school graduate or with some college, have public/military insurance, have any type of usual source of care, and be at high risk for influenza.

\section{H1N1 Vaccination (model 1)}

Table 2 shows the ORs and 95\%CIs associated with each explanatory variable from the multivariable logistic regression model predicting H1N1 vaccination (Model 1). The results show that the odds of a Veteran obtaining the H1N1 vaccine was 1.30 times $(95 \% \mathrm{CI}(1.09,1.55), \mathrm{p}<0.01)$ the odds of a non-Veteran receiving the $\mathrm{H} 1 \mathrm{~N} 1$ vaccine. Males $(\mathrm{OR}=0.73, \quad 95 \% \quad \mathrm{CI} \quad(0.65,0.82), \quad \mathrm{p}<0.001)$, blacks $(\mathrm{OR}=0.73, \quad 95 \%$ CI $(0.62,0.85), \quad \mathrm{p}<0.001)$, smokers $(\mathrm{OR}=0.74,95 \% \mathrm{CI}(0.64,0.86), \mathrm{p}<0.001)$, and those who lacked usual source of care $(\mathrm{OR}=0.52,95 \% \mathrm{CI}(0.43,0.64)$, $\mathrm{p}<0.001)$ had lower odds of obtaining the H1N1 vaccine. Veterans, college graduates $(\mathrm{OR}=1.80,95 \% \mathrm{CI}(1.49,2.19)$, $\mathrm{p}<0.001)$ or some college $(\mathrm{OR}=1.29,95 \% \mathrm{CI}(1.07,1.55)$, $\mathrm{p}<0.01)$, private $(\mathrm{OR}=1.52,95 \% \mathrm{CI}(1.25,1.85), \mathrm{p}<0.001)$, or public/military health insurance $(\mathrm{OR}=1.78,95 \% \mathrm{CI}$ (1.44, 2.21), $\mathrm{p}<0.001)$, and those at high risk $(\mathrm{OR}=1.51$,
Table 2 Odds ratios (OR) with $95 \%$ confidence intervals $(95 \% \mathrm{Cl})$ from models predicting receipt of $\mathrm{H} 1 \mathrm{~N} 1$ vaccine (H1N1) and receipt of seasonal flu vaccine (Seasonal)

\begin{tabular}{|c|c|c|c|c|c|}
\hline & & H1N1 & & Seasonal & \\
\hline & & $\overline{O R}$ & $95 \% \mathrm{Cl}$ & $\overline{O R}$ & $95 \% \mathrm{Cl}$ \\
\hline Veteran & No & Ref & & Ref & \\
\hline Status & Yes & $1.30^{* *}$ & $1.09,1.55$ & $1.42^{* * *}$ & $1.23,1.66$ \\
\hline Age & $18-24$ & Ref & & Ref & \\
\hline \multirow[t]{3}{*}{ Categories } & $25-44$ & 1.04 & $0.91,1.20$ & $1.19^{* *}$ & $1.06,1.34$ \\
\hline & $45-64$ & $1.34^{* *}$ & $1.10,1.63$ & $1.88^{* * *}$ & $1.63,2.18$ \\
\hline & 65 up & $1.27^{*}$ & $1.01,1.59$ & $3.05^{* * *}$ & $2.54,3.65$ \\
\hline \multirow[t]{2}{*}{ Gender } & Female & Ref & & Ref & \\
\hline & Male & $0.73^{* * *}$ & $0.65,0.82$ & $0.65^{* * *}$ & $0.59,0.72$ \\
\hline \multirow[t]{4}{*}{ Race } & White & Ref & & Ref & \\
\hline & Black & $0.73^{* * *}$ & $0.62,0.85$ & $0.81^{* *}$ & $0.71,0.94$ \\
\hline & Hispanic & 1.06 & $0.92,1.22$ & 0.94 & $0.82,1.07$ \\
\hline & Other & $1.24^{*}$ & $1.03,1.48$ & 1.15 & $0.98,1.35$ \\
\hline Marital & Married & Ref & & Ref & \\
\hline \multirow[t]{2}{*}{ Status } & Div/Sep/Wid & 0.89 & $0.77,1.02$ & $0.85^{* *}$ & $0.75,0.95$ \\
\hline & Never/Single & 0.93 & $0.78,1.09$ & $0.78^{* * *}$ & $0.68,0.89$ \\
\hline Children & None & Ref & & Ref & \\
\hline < 18 Living & $1-2$ kids & $1.18^{*}$ & $1.01,1.37$ & $0.87^{*}$ & $0.77,0.97$ \\
\hline in $\mathrm{HH}$ & 3 or more kids & 1.15 & $0.94,1.40$ & 0.84 & $0.69,1.01$ \\
\hline \multirow[t]{4}{*}{ Education } & Not HS & Ref & & Ref & \\
\hline & HS Grad & 1.06 & $0.89,1.28$ & 1.04 & $0.90,1.20$ \\
\hline & Some Coll & $1.29^{* *}$ & $1.07,1.55$ & 1.17 & $0.99,1.37$ \\
\hline & Coll Grad & $1.80^{* * *}$ & $1.49,2.19$ & $1.58^{* * *}$ & $1.34,1.86$ \\
\hline \multirow[t]{2}{*}{ Smoking } & No & Ref & & Ref & \\
\hline & Yes & $0.74^{* * *}$ & $0.64,0.86$ & $0.69^{* * *}$ & $0.60,0.78$ \\
\hline Health & None & Ref & & Ref & \\
\hline \multirow[t]{2}{*}{ Insurance } & Private & $1.52^{* * *}$ & $1.25,1.85$ & $1.62^{* * *}$ & $1.36,1.93$ \\
\hline & Pub/Mil & $1.78^{* * *}$ & $1.44,2.21$ & $2.09^{* * *}$ & $1.72,2.55$ \\
\hline Family & $0-\$ 15 k$ & Ref & & Ref & \\
\hline \multirow[t]{2}{*}{ Income } & $\$ 15 k-\$ 35 k$ & 1.02 & $0.87,1.19$ & 1.14 & $0.99,1.30$ \\
\hline & $\$ 35 \mathrm{k}+$ & 1.04 & $0.90,1.20$ & $1.24^{* * *}$ & $1.11,1.40$ \\
\hline \multirow[t]{2}{*}{ Employed } & No & Ref & & Ref & \\
\hline & Yes & 1.00 & $0.88,1.12$ & 1.07 & $0.96,1.20$ \\
\hline Usual Source & Clinic & Ref & & Ref & \\
\hline \multirow[t]{3}{*}{ of Care } & MD Office & $0.86^{*}$ & $0.76,0.97$ & 1.04 & $0.91,1.17$ \\
\hline & Neither & 0.79 & $0.58,1.08$ & 0.86 & $0.66,1.11$ \\
\hline & None & $0.52^{* * *}$ & $0.43,0.64$ & $0.52^{* * *}$ & $0.43,0.63$ \\
\hline \multirow[t]{2}{*}{ High Risk } & No & Ref & & Ref & \\
\hline & Yes & $1.51^{* * *}$ & $1.36,1.67$ & $1.47^{* * *}$ & $1.33,1.63$ \\
\hline
\end{tabular}

$\mathrm{N}=15339$.

${ }^{*} p<0.05,{ }^{* *} p<0.01,{ }^{* * *} p<0.001$. 
$95 \%$ CI $(1.36,1.67), \mathrm{p}<0.001)$ had greater odds of obtaining the H1N1 vaccine.

\section{Seasonal Flu vaccination (model 2)}

Table 2 shows that Veterans were significantly more likely to obtain the seasonal flu vaccine than nonVeterans. The odds of a Veteran obtaining the seasonal flu vaccine was 1.42 times the odds of a non-Veteran receiving the vaccine $(95 \%$ CI $(1.23,1.66), \mathrm{p}<0.001)$. Each age group tested $(25-44,45-64, \geq 65)$ was significantly more likely to get a seasonal flu vaccine compared to the reference group $(18-24)$ (p's $<0.01)$. Males $(\mathrm{OR}=0.65$, $95 \%$ CI $(0.59,0.72), \mathrm{p}<0.001)$, blacks $(\mathrm{OR}=0.81,95 \%$ CI $(0.71,0.94), \mathrm{p}<0.01)$, divorced/separated/widowed ( $\mathrm{OR}=0.85,95 \% \mathrm{CI}(0.75,0.95), \mathrm{p}<0.01)$, never married/ single $(\mathrm{OR}=0.78, \quad 95 \%$ CI $(0.68, \quad 0.89), \quad \mathrm{p}<0.001)$, smokers $(\mathrm{OR}=0.69,95 \% \mathrm{CI}(0.60,0.78), \mathrm{p}<0.001)$, and those with no usual source of care $(\mathrm{OR}=0.52,95 \% \mathrm{CI}$ $(0.43,0.64), \mathrm{p}<0.001)$ had lower odds of receiving the seasonal flu. College graduates $(\mathrm{OR}=1.58,95 \% \mathrm{CI}(1.34$, $1.86), \mathrm{p}<0.001)$, those with private insurance $(\mathrm{OR}=1.62$, $95 \%$ CI $(1.36,1.93), \mathrm{p}<0.001)$ or public/military insurance $(\mathrm{OR}=2.09,95 \% \mathrm{CI}(1.72,2.55), \mathrm{p}<0.001)$, the highest income group (OR $=1.24,95 \%$ CI $(1.11, .40)$, $\mathrm{p}<0.001)$, and those at high risk $(\mathrm{OR}=1.47,95 \% \mathrm{CI}$ $(1.33,1.63), \mathrm{p}<0.001)$ had greater odds of receiving the vaccine.

\section{H1N1 vs. Seasonal Flu vaccination}

Table 3 shows tests of the equality of the coefficients from Model 1 (H1N1 flu) and Model 2 (seasonal flu). The effect of age and number of children significantly differed for Model 1 compared to Model 2 ( $\mathrm{p}<0.01$ ). The overall test comparing the coefficients associated with the four levels of

Table 3 Tests of the equality of the effects (coefficients) from Model 1 (H1N1 flu) compared to Model 2 (seasonal flu)

\begin{tabular}{llll}
\hline Variable & df & F test & p-value \\
\hline Veteran Status & 1 & 1.36 & .245 \\
Age & 3 & 25.10 & $<0.001$ \\
Gender & 1 & 3.73 & .054 \\
Race & 3 & 1.91 & .127 \\
Marital Status & 2 & 1.09 & .338 \\
Children $<18$ in HH & 2 & 9.43 & $<0.001$ \\
Education & 3 & .88 & .452 \\
Family Income & 2 & 2.45 & .088 \\
Employed & 1 & 0.73 & .394 \\
Health Insurance & 1 & 1.22 & .269 \\
Smoking & 1 & 1.35 & .247 \\
Usual Source of Care & 3 & 3.71 & .012 \\
High Risk & 1 & 0.19 & .667 \\
\hline
\end{tabular}

age showed significant differences between Model 1 and Model 2 ( $p<0.001)$. Tests of each of the individual coefficients for age showed that the coefficient comparing ages 25 to 44 to the reference group (18 to 24 ) was not significant $(\mathrm{p}=0.067)$, however the coefficient for ages 45 to 64 $(\mathrm{p}<0.003)$ and for age 65 and up $(\mathrm{p}<0.001)$ were significant. The effect of being in these older age categories (4564 and 65\&up) as compared to the reference group (18 to 24) was greater for the seasonal flu vaccine compared to the H1N1 vaccine.

\section{Discussion}

According to predisposing, enabling and need factors identified in the Anderson Behavioral Model, there were significant differences between Veterans and non-Veterans on characteristics such as gender, race, age, marital status, employment status, education, health insurance, type of usual source of care, and high-risk status. These initial findings guided the inclusion of selected set of independent variables in the models analyzing flu vaccination by Veteran status. The results of this study confirm previous findings and provide important additions to the current literature about comparisons in influenza and H1N1 vaccinations among Veterans and non-Veterans using the 2010 NHIS. The findings indicate that Veterans, women, non-Hispanic whites, those with higher education, non-smokers, those with health insurance (private or public/military), those with a clinic as a usual source of care, and those who are high risk were more likely to receive both types of vaccinations, which is largely consistent with findings from previous studies $[8,10,21,23,24,30]$. Age, marital status, and family income were additional significant correlates of using the seasonal flu vaccine, which is also consistent with previous studies $[8,24]$ (i.e. older age groups, those who are married, and those with more income were more likely to get vaccinated for seasonal flu). The finding on age may in part reflect the impact of public information campaigns of the Center for Medicare and Medicaid Services, which actively promotes the use of vaccines for seasonal flu [31]. Use of the H1N1 vaccine was not sensitive to differences in income, perhaps because of the urgent nature of the pandemic, i.e. the strength of the perceived threat surpassed concerns about financial cost. Similarly, the social support and encouragement for vaccine use that one receives from a spouse may not be as important when the perceived health threat is relatively high, as was likely the case with the unexpected global pandemic of H1N1.

The dataset used in this study does not include a measure of where the Veteran received a vaccination. The VA is not a health insurance system, but rather a separate integrated healthcare system that is accessible by qualified Veterans. In general, the use of preventive care among VA-users is higher than the general public. This may account for at least some of the relatively higher use of vaccinations 
among Veterans compared to non-Veterans. Although this finding is encouraging, the use of vaccinations among Veterans is still significantly lower than is recommended by the CDC and more efforts should be made to promote greater use of vaccinations among Veterans.

The study tested the equality of the coefficients for H1N1 and seasonal influenza vaccination. Statistically significant differences in the effect of age and number of children living in the household were found for H1N1 compared to seasonal flu. For seasonal flu, all three older age groups were more likely to receive vaccination compared to 18-24 year olds. For H1N1, however, this pattern was not found - i.e. the older groups were just as likely to get vaccinated as the youngest age group $(18-24)$. It is possible that seasonal flu is generally perceived as a pathogen to which one becomes more susceptible with age, whereas $\mathrm{H} 1 \mathrm{~N} 1$ is perceived as a threat to all, regardless of age. Similarly, different patterns were found for number of children living in households - those with children were less likely to receive seasonal flu vaccination whereas for $\mathrm{H} 1 \mathrm{~N} 1$, those with children were more likely to receive $\mathrm{H} 1 \mathrm{~N} 1$ vaccination. People with more children may be more so accustomed to dealing with upper respiratory tract infections that seasonal flu might seem more "normal" and manageable, whereas H1N1 might seem more unpredictable and threatening, thus motivating the use of vaccine. Moreover, the aforementioned news reports in 2010 suggesting that $\mathrm{H} 1 \mathrm{~N} 1$ placed children at greater risk of morbidity or mortality than did seasonal influenza likely motivated parents/guardians to have their children vaccinated for H1N1 [32,33].

There are strengths and limitations of this study. The strengths of this study are that it used a nationally representative sample of both Veterans and non-Veterans providing comparable data on influenza and $\mathrm{H} 1 \mathrm{~N} 1$ vaccination for both groups. The statistical method used in the analyses reliably mirrored receipt of vaccination for these two groups assessing whether the various indictors of immunization varied between Veterans and nonVeterans. The study has some limitations. Due to lack of data, patient preferences or attitudes towards vaccination were not included in the analyses. Previous research has shown factors such as fear of side effects from vaccination [34], efficacy concerns [34,35], doctor recommendation [34], and the fear that vaccination actually causes influenza $[34,36]$ to have an effect on the likelihood of getting vaccinated. To the extent that any omitted variables are associated with the variables that we were able to include in our analyses, the multivariate models may at least partially account for their effects. Nevertheless, future work should include variables on preferences, attitudes, and other such characteristics whenever possible. Also, potential differences in vaccination use among Veterans using the VA health care system, Veterans not using the VA health care system, and Veterans who use both VA and non-VA health care is certainly worthy of study. Unfortunately, the lack of NHIS data on VA system use does not permit comparisons of vaccination use among these three groups. The data used in the analyses were cross-sectional, limiting the extent to which causality could be assessed; however, reverse causality is not a major concern for the key question about the relationship between Veteran status and vaccination use.

\section{Conclusion}

In summary, the findings from this study show that Veterans are more likely to get vaccinated than are nonVeterans. This suggests that there may be effective ways to improve vaccination rates among other populations that are socioeconomically disadvantaged or otherwise vulnerable. The observed differences in vaccination rates may be due to some Veterans having better access to care because they qualify to use the VA, or other potential differences related to Veterans health care practices and attitudes toward prevention. Future studies should examine whether better access to care for other vulnerable populations can also lead to higher vaccination rates among other groups. Regardless of Veteran status, the determinants of vaccination use are different for H1N1 and seasonal influenza for certain population subgroups, suggesting areas for improving immunization rates among both Veteran and non-Veteran populations. From a policy perspective, the findings on family income and marital status suggest that outreach programs for people from lower-income backgrounds or who may be more isolated (widowed, never married, etc.) would be more effective at improving access to vaccinations for seasonal flu than H1N1. In an integrated delivery system such as the VA, electronic reminder systems have been successfully used at point of care to increase adherence to clinical practice guidelines for a number of health conditions and services, including vaccinations. However, efforts are needed to improve the delivery of care to all Veterans, both VA health care system users and non-users alike.

\section{Abbreviations}

VA: Department of Veterans Affairs; NHIS: National Health Interview Survey; CDC: Centers for Disease Control and Prevention; ACIP: Advisory Committee on Immunization Practices.

\section{Competing interests}

The authors declare that they have no competing interests.

\section{Authors' contribution}

CDM conceived the study, participated in its design, and drafted the manuscript. KCH participated in its design, assisted in writing and editing the manuscript. MNM performed the statistical analysis and interpreted the findings. KC performed the statistical analysis and edited the manuscript. KT 
assisted in critically revising the manuscript. AD participated in the design of the study, drafted the manuscript and revised it critically. All authors read and approved the final manuscript.

\section{Authors' information}

Claudia Der-Martirosian, PhD is a research health scientist at the Department of Veterans Affairs' (VA) Veterans Emergency Management Evaluation Center (VEMEC) with over 15 years of research experience quantitative research methods. Prior to joining VEMEC, she was a senior statistician at UCLA, UC San Diego, and UC Davis. Her research experience includes one book publication and over 50 first-authored and co-authored publications in health related fields such as public health, quality of life, and medical education.

Kevin C. Heslin, PhD is a research health scientist at VEMEC. His research focuses on access to health services and health outcomes in marginalized populations, particularly among individuals with substance use disorders. With his colleagues in VEMEC, he has conducted work on disaster preparedness among U.S. veterans in California, as well as the differential impact of the 1994 Northridge earthquake on veterans with screening positive for substance abuse or dependence. Currently he is examining the impact of Hurricane Ike on veterans' access to methadone maintenance therapy in the Houston, Texas area. Dr. Heslin received his Ph.D. from the Department of Health Management and Policy at UCLA, and was a predoctoral fellow in the National Institute of Mental Health/UCLA AIDS Research Training Program.

Michael N. Mitchell, PhD was a senior statistician at VEMEC, at the time this manuscript was developed. He is the author of Interpreting and Visualizing Regression Models Using Stata, A Visual Guide to Stata Graphics, as well as Data Management Using Stata. Previously, he worked for 12 years as a statistical consultant and manager of the UCLA ATS Statistical Consulting Group where he envisioned the UCLA Statistical Consulting Resources website and wrote hundreds of web pages about the use of SAS, Stata, SPSS, and other statistical computing packages.

Karen Chu, MS is a statistician for VEMEC and the VA Health Services Research and Development Center of Innovation (HSR\&D). Ms. Chu has a Master of Science in Pharmaceutical Economics and Policy from the University of Southern California. She has experience working with medical claims databases, national survey data, quality of life data, and clinical trial data. She is primarily responsible for coordinating the use of various VA and non-VA datasets for research, extraction, and analysis.

Kim Tran PhD, RN, a nurse practitioner, completed her baccalaureate training in nursing at the University of Southern California in 1997. She completed her doctoral training at the UCLA School of Nursing in 2006 where she also obtained her Master's degree. Her research interest is in health disparities and examining access to care among vulnerable populations using quantitative and qualitative methods. She has worked in the critical care and coronary care settings as a registered nurse and as a nurse practitioner for over 15 years. Previously, she was an Assistant Professor at California State University of Los Angeles where she taught both undergraduate and graduate nursing students. She was a postdoctoral fellow at the Department of Veterans Affairs HSR \&D Center of Excellence for the Study of Healthcare Provider Behavior as well as a UCLA faculty in the School of Nursing at the time this manuscript was developed.

Aram Dobalian, PhD, JD is the founding Director of the U.S. Department of Veterans Affairs' (VA) Veterans Emergency Management Evaluation Center (VEMEC). VEMEC's work focuses on cutting-edge policy and operations questions that support VA's emergency management responsibilities - to improve the Nation's preparedness for response to war, terrorism, national emergencies, and natural disasters by ensuring continuity of veteran care, and to support national, state, and local emergency management, public health, safety, and homeland security efforts.

\section{Acknowledgments}

This material is based upon work supported by the Department of Veterans Affairs, Veterans Health Administration, Office of Public Health (OPH). The views expressed in this article are those of the authors and do not necessarily reflect the position or policy of the Department of Veterans Affairs or the U.S. government.

\section{Author details}

${ }^{1}$ Veterans Emergency Management Evaluation Center (VEMEC), Department of Veterans Affairs, North Hills, California, USA. ${ }^{2}$ School of Nursing, University of California, Los Angeles, USA. ${ }^{3}$ Fielding School of Public Health, University of California, Los Angeles, USA.

Received: 30 May 2013 Accepted: 15 November 2013 Published: 20 November 2013

\section{References}

1. WHO 2012 Influenza. http://www.who.int/mediacentre/factsheets/2003/ fs211/en/.

2. Adult vaccination coverage - United States, 2010. MMWR Morb Mortal Wkly Rep 2012, 61:66-72

3. Kunisaki KM, Janoff EN: Influenza in immunosuppressed populations: a review of infection Prevention and control of influenza with vaccines: recommendations of the Advisory Committee on Immunization Practices (ACIP), 2011. Am J Transplant 2011, 11(10):2250-5.

4. Glezen WP, Greenberg SB, Atmar RL, Piedra PA, Couch RB: Impact of respiratory virus infections on persons with chronic underlying conditions. JAMA 2000, 283:499-505.

5. Fiore AE, Uyeki TM, Broder K, Finelli L, Euler GL, Singleton JA, et al: Prevention and control of influenza with vaccines: Recommendations of the Advisory Committee on Immunization Practices (ACIP), 2010. MMWR Recomm Rep 2010, 59(RR-8):1-62.

6. Prevention and Control of Influenza with Vaccines: Recommendations of the Advisory Committee on Immunization Practices (ACIP), 2011. MMWR Morb Mortal Wkly Rep 2011, 60(33):1128-1132.

7. U.S. Department of Health and Human Services 2012. Healthy People 2020. Leading Health Indicators: Clinical Preventive Services. http://www. healthypeople.gov/2020/LH//clinicalPreventive.aspx. Accessed August 10, 2012.

8. Lu P, Singleton JA, Rangel MC, Wortley PM, Bridges CB: Influenza vaccination trends among adults 65 years or older in the United States, 1989-2002. Arch Intern Med 2005, 165:1849-1856.

9. Zimmerman RK, Santibanez TA, Janosky JE, Fine MJ, Raymund M, Wilson SA, Bardella IJ, Medsger AR, Nowalk MP: What affects influenza vaccination rates among older patients? An analysis from inner-city suburban, rural and Veteran Affairs practices. Am J Med 2003, 114:31-38.

10. Peterson RL, Saag K, Wallace RB, Doebbling BN: Influenza and pneumococcal vaccine receipt in older persons with chronic disease: a population-based study. Med Care 1999, 37:502-509.

11. Influenza and pneumococcal vaccination levels among adults aged >= 65 years - United States. MMWR 1998, 47(38):797-802.

12. Nichol KL, Margolis KL, Wuorenma J, Von Sternberg T: The efficacy and cost effectiveness of vaccination against influenza among elderly persons living in the community. N Engl J Med 1994, 331:778-784.

13. Jhung MA, Swerdlow D, Olsen SJ, Jernigan D, Biggerstaff M, Kamimoto L, et al: Epidemiology of 2009 pandemic influenza A (H1N1) in the United States. Clin Infect Dis 2011, 52(Suppl 1):S13-26.

14. Harris KM, Maurer J, Uscher-Pines L: Seasonal influenza vaccine use by adults in the US; 2009.

15. Maurer J, Harris KM, Parker A, Lurie N: Does receipt of seasonal influenza vaccine predict intention to receive novel H1N1 vaccine: evidence from a nationally representative survey of U.S. adults. Vaccine 2009, 27(42):5732-5734.

16. Koepsell T, Reiber G, Simmons KW: Behavioral risk factors and use of preventive services among Veterans in Washington state. Prev Med 2002, 35:557-562.

17. Agha Z, Lofgren RP, VanRuiswyk JV, Layde PM: Are patients at Veterans Affairs medical centers sicker? Arch Intern Med 2000, 160:3252-3257.

18. Strategic Plan Refresh FY2011-2015. Washington DC: Department of Veterans Affairs, Office of the Secretary. http://www.va.govNA_2011-2015_Strategic_ Plan_Refresh_wv.pdf.

19. Bean-Mayberry B, Yano EM, Mor MK, Bayliss NK, Xu X, Fine MJ: Does gender influence immunization status for influenza and pneumonia among older Veterans? J Am Geriatr Soc 2009, 57(8):1427-1432.

20. VA Influenza Manual 2008/2009. Department of Veterans Affairs, Office of Public Health and Environmental Hazards. http://www1.va.gov/ vhapublications/ViewPublication.asp?pub_ID $=1978$.

21. Lynch CP, Strom JL, Egede LE: Variation in quality of care indicators of diabetes in a national sample of Veterans and non-Veterans. Diabetes Technol Ther 2010, 12:785-790. 
22. Centers for Disease Control and Prevention: Influenza and pneumococcal vaccination levels among persons aged $\geq 65$ years - United States, 1999. MMWR Morb Mortal Wkly Rep 2001, 50:532-537.

23. van Essen GA, Kuyvenhoven MM, de Melker RA: Why do healthy elderly people fail to comply with influenza vaccination? Age Ageing 1997, 26:275-279.

24. Andrew MK, McNeil S, Merry H, Rockwood K: Rates of influenza vaccination in older adults and factors associated with vaccine use: a secondary analysis of the Canadian Study of Health and Aging. BMC Public Health 2004, 4:36.

25. Claver M, Friedman D, Dobalian A, Ricci K, Horn-Mallers M: The role of veterans affairs in emergency management: a systematic literature review. PLOS Currents: Disasters; 2012. Dec 12. Edition 1. doi:10.1371/ 198d344bc40a75f927c9bc5024279815.

26. Andersen RM, Davidson PL: Improving access to health care in America: Individual and contextual indicators. In Changing the U.S. health care systems: key issues in health services policy and management. 3rd edition. Edited by Andersen RM, Rice TH, Kominski GH. San Francisco: Jossey-Bass/ Wiley \& Sons Inc.; 2007.

27. Andersen RM: Revisiting the behavioral model and access to medical care: does it matter? J Health Soc Behav 1995, 36(1):1-10

28. Johnson PJ, Blewett LA, Ruggles S, Davern ME, King ML: Four decades of population health data: the Integrated Health Interview Series as an epidemiologic resource. Epidemiology 2008, 19(6):872.

29. Variance Estimation and Other Analytic Issues, NHIS 2006-2011; 2012. http://www.cdc.gov/nchs/data/nhis/2006var.pdf.

30. Lu P, Bridges CB, Euler $G L$, Singleton JA: Influenza vaccination of recommended adult populations, U.S. 1989-2005. Vaccine 2008, 26:1786-1793.

31. Medicare Learning Network: 2011-2012 Seasonal Influenza (Flu) Virus Educational Products and Resources. Center for Medicare and Medicaid Services; 2010. http://www.cms.gov/Outreach-and-Education/MedicareLearning-Network-MLN/MLNProducts/downloads/Flu_Products.pdf.

32. CDC H1N1 Flu 2009 H1N1 Recommendations / Novel H1N1 Recommendations Oct 15, 2009. http://www.cdc.gov/h1n1flu/vaccination/acip.htm.

33. CDC HIN1 Flu 2009 Updated Interim Recommendations for the use of antiviral medications in the treatment and prevention of influenza for the 2009-2010 season; 2009. http://www.cdc.gov/h1n1flu/recommendations.htm.

34. Centers for Disease Control and Prevention: Reasons reported by Medicare beneficiaries for not receiving influenza and pneumococcal vaccinations - United States, 1996. MMWR Morb Mortal Wkly Rep 1999, 43:886-889.

35. Fiebach NH, Viscoli CM: Patient acceptance of influenza vaccination. Am J Med 1991, 91:393-400.

36. Nichol KL, Lofgren RP, Gapinkski J: Influenza vaccination. Knowledge, attitudes, and behavior among high-risk outpatients. Arch Intern Med 1992, 152:106-110.

doi:10.1186/1471-2458-13-1082

Cite this article as: Der-Martirosian et al: Comparison of the Use of H1N1 and seasonal influenza vaccinations between veterans and nonveterans in the United States, 2010. BMC Public Health 2013 13:1082.

\section{Submit your next manuscript to BioMed Central and take full advantage of:}

- Convenient online submission

- Thorough peer review

- No space constraints or color figure charges

- Immediate publication on acceptance

- Inclusion in PubMed, CAS, Scopus and Google Scholar

- Research which is freely available for redistribution

Submit your manuscript at www.biomedcentral.com/submit 